\title{
Analytically Determining Bond Shear Strength of Fully Grouted Rock Bolt Based on Pullout Test Results
}

\author{
Mousa Hazrati Aghchai ${ }^{1}$, Parviz Maarefvand ${ }^{1 *}$, Hossein Salari Rad $^{1}$ \\ 1 Department of Mining Engineering, Faculty of Mining and Metallurgical Engineering, Amirkabir University of Technology \\ 424 Hafez Ave, Tehran, Iran, P.O.B. 159163-4311 \\ *Corresponding author, e-mail: parvizz@aut.ac.ir
}

Received: 29 October 2019, Accepted: 25 December 2019, Published online: 03 February 2020

\begin{abstract}
Usually, in a fully grouted rock bolt pullout test the load-displacement curve of the rock bolt head is recorded. This paper presents an analytical method to use this curve for determining the bond (bolt-grout and grout-rock interface) shear strength parameters. For this purpose, the fully grouted rock bolt interaction with grout and surrounding rock in the pullout test is investigated and the loaddisplacement curve of the bolt head (beginning of the bonded section) is obtained analytically. For modeling the bolt-grout interface behavior a distribution of the shear stress along the fully grouted rock bolt by consideration of bolt shank failure is used. In this regard, different stages including complete bonding, partial decoupling, decoupling with the residual shear strength and complete decoupling are considered. With increasing the applied load, two possible cases involving the rock bolt complete pullout and bolt shank yielding are taken into account. Based on the presented analytical method, the obtained bolt head load-displacement curve can be compared with the one recorded in the pullout test. With this, the relevance of selected shear strength parameters compared to real parameters can be assessed. A flowchart for determining the bolt bond shear strength parameters is presented using the trial and error method (coded in Matlab). The proposed solution is used to determine two experimental pullout shear strength parameters. The results show good agreement between predicted and calculated load-displacement curves.
\end{abstract}

Keywords

load-displacement curve, fully grouted rock bolt, pullout test, bond shear strength

\section{Introduction}

Fully grouted rock bolts are frequently used for rock reinforcement and stabilization of underground and surface excavations. Grouted rock bolts are usually inserted in a drilled hole and interact with the surrounding medium via cement based or resin grout. To evaluate the load bearing capacity of bonded (grouted or anchored) bolts or to control the installation quality of rock bolts (acceptable anchorage), pullout tests are performed based on ISRM suggested method or ASTM standard [1,2]. The output of the pullout test is typically a load-displacement curve of the bolt head. Understanding bolt-grout-rock interaction in pullout tests helps in designing the rock bolts for reinforcement.

Determining the pullout capacity of rock bolt is immensely important in design of anchorages in civil and mining engineering such as pre-tensioned rock bolts in caverns, transmission tower foundation, and suspension of rock blocks [3]. The capacity depends on the shear strength characteristics of the bolt-grout and the grout-rock contact.
So, determining the bond shear strength parameters is very important in design of underground and surface structures.

Many researchers have investigated the bolt-grout-rock interaction. Farmer [4] was one of the first researchers who presented a solution for determining the distribution of axial stress and displacement in grouted rock bolts and the shear stress in the contact between bolt and grout. He proposed an exponential relationship for decreasing stress along the rock bolt in complete bonding and elastic condition. Li and Stillborg [5] considered decoupling in the bolt-grout contact based on pullout experimental results. They presented an analytical model for the distribution of axial stress in the bolt and shear stress at the bolt-grout contact in a pullout test, in uniform displacement of rock mass, and in a joint opening. They have not considered bolt shank failure. He et al. [6] used a similar assumption by including bolt shank failure. They considered long and short rock bolt pullout test, but did not 
give a solution for the bolt head load-displacement curve. They presented a method for increasing load as a result of joint opening. Benmokrane et al. [7] presented a tri-linear bond slip model based on experimental pullout tests performed on bolts and cables of short length. Ren et al. [8], Martin et al. [9] and Shuqi Ma et al. [10] used the tri-linear bond-slip model and presented a solution for determining load-displacement curve of the bolt head. They did not take into account the bolt shank failure, but they introduced small residual shear strength. Ma et al. [11] presented an analytical method for fully grouted rock bolt using a tri-linear bond-slip relationship considering post-yielding characteristics of the rock bolt material. They did not evaluate bond shear strength based on bolt head load-displacement curve.

This paper develops the model proposed by $\mathrm{Li}$ and Stillborg [5] by considering the bolt shank failure to determine the bolt head load-displacement curve analytically. Then a method is proposed to define the bond shear strength parameters by comparing the predicted load-displacement curve with the one obtained in a real pullout test. It is important to note that the proposed method is applicable even if the bolt is not pulled out completely (either the bolt shank yields or the test is stopped before bolt total pullout).

\section{Model assumptions}

A sketch of a relatively long rock bolt pullout test is illustrated in Fig. 1. In the fully grouted rock bolt, the bond length $(L b)$ is equal to the bolt length inside the hole and the free length $(L f)$ is the distance between the loading point and the hole head. $L f$ is usually the loading jack length. In a partially grouted rock bolt, the free length $(L f)$

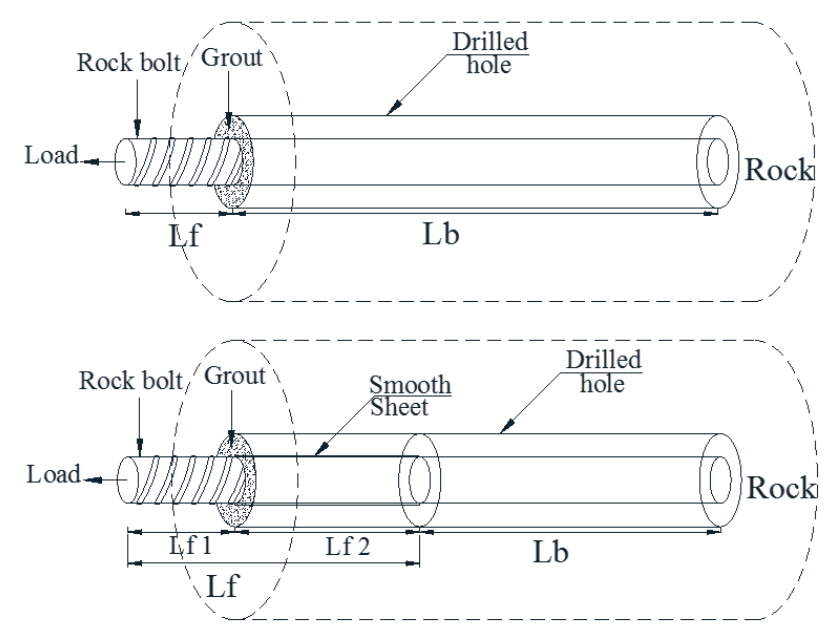

Fig. 1 Sketch of a rock bolt pullout test, a) fully grouted rock bolt; b) partially grouted rock bolt, $(L f=$ free length, $L b=$ bond length) includes the de-bonded section ( $L f 2)$ inside the hole (usually made by a smooth sheet) plus the free length outside the hole $(L f 1)$. The remaining bolt length inside the hole is the bond length $(L b)$.

The rock bolt (assuming a ribbed steel bar with cross section $A_{b}$, diameter $d_{b}$, and elastic modulus $E_{b}$ ) interacts with the surrounding rock in the bonded section via a grout (a cement based mortar or resin). The grout provides the coupling at the interfaces (bolt-grout contact and grout-rock contact) [5].

Based on Windsor classification [12], the grouted rock bolt in the bonded section is categorized as continuously mechanically coupled (CMC). In the free length section, the bolt acts as a steel bar under tension (independent from the surrounding rock).

By applying a load on the rock bolt head, displacement occurs in the bar, in the grout, and in the rock. During a pullout test, usually, the elongation of the rock bolt in the loading point versus the applied load is recorded, which results in a load-displacement curve. The stress-strain equation of the rock bolt free length is just its elongation as a result of the applied load. It can be added to the elongation of the rock bolt bonded length; thus, the model in this paper concentrates on determining analytically the load-displacement curve in the bonded length (start of the grouted/bonded section). Based on this, the bond shear strength characteristics are determined.

Increasing the applied load can cause a failure either in the bolt shank, in the bolt-grout interface, inside the grout, in the grout-rock interface, or inside the rock, depending on the weakest point [6]. In this paper failure of grout and surrounding rock is not considered. It is assumed that they remain elastic. Failure is considered to occur either on the interface or in the bolt shank (steel bar).

For the grouted section of the rock bolt, the model by $\mathrm{Li}$ and Stillborg [5] as well as He et al. [6] for the shear stress distribution along the interface is considered, as presented in Fig. $2[5,6]$. The so-called decoupling front initiates and propagates along the bolt by increasing the applied load. In this paper, it is postulated that as long as the rock bolt shank is elastic, a residual shear strength $(\mathrm{Sr})$ exists in the interface (shear stress will not be zero). When the rock bolt shank reaches its yield limit, complete decoupling happens at a specific distance from the loading point $\left(x_{0}\right)$ and the shear stress at the bolt interface will be zero (Fig. 2).

The residual shear strength exists up to a point $\mathrm{x} 1$; then, it increases gradually to peak shear strength $(S p)$ within a distance from $x_{1}$ to $x_{2}\left(\Delta=x_{2}-x_{1}\right)$. In the decoupling front 


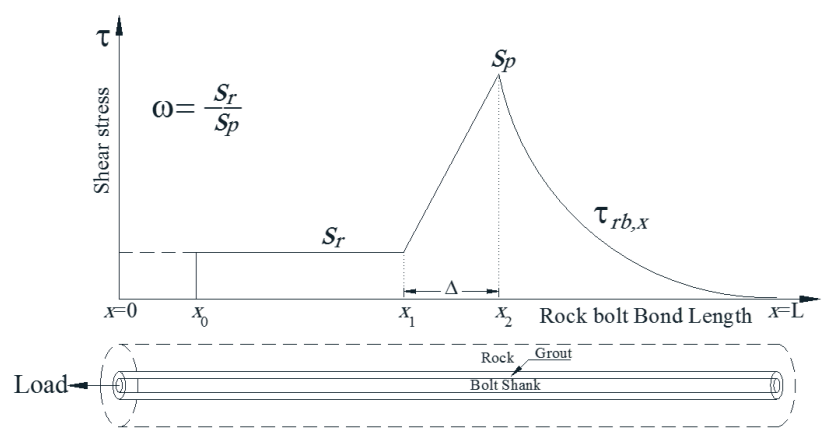

Fig. 2 Assumed interface shear stress distribution along the rock bolt bond length $[5,6]$

(point $x_{2}$ ) shear stress at the interface is equal to the peak shear strength. Beyond this point $\left(x_{2}\right)$, deformation in the interface is compatible and the shear stress $\left(\tau_{r b, x}\right)$ attenuates toward the far end of the rock bolt [3-6].

To reach this shear stress distribution along the bolt, the behavior of interface (at each infinitesimal element) during shearing is assumed to be elastic-softening-residual type.

A simplified model is assumed for the rock bolt shank (steel bar) obeying the elasto-plastic constitutive model of steel material [6], as shown in Fig. 3.

Under increasing tensile stress, the bar strain increases elastically with a constant rate of $E_{b}$ (elasticity modulus) until the elastic strain and stress reach the yielding limit $\left(\varepsilon_{y}, \sigma_{y}\right)$. The yielding stress remains constant until the strain reaches the $\varepsilon_{h 1}$ limit. Then, growing stress causes more strain with the rate of $E_{t}$ (hardening stage) to reach the ultimate stress and strain level $\left(\varepsilon_{h 2}, \sigma_{u}\right)$. In this point, the stain increases constantly at the same stress level to reach the $\varepsilon_{u}$ limit (in which necking and failure of bar occurs).

It should be noted that dilation behavior at the bolt-grout and the grout-rock interface and the resulted normal stress, which is a function of surrounding medium stiffness, is not

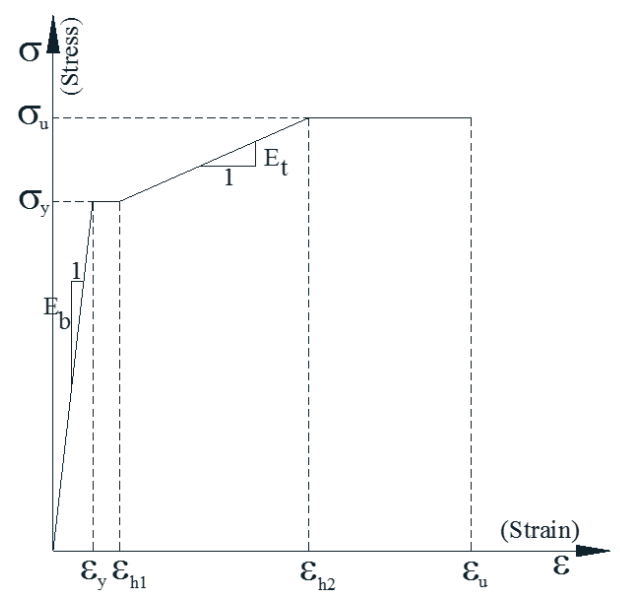

Fig. 3 Constitutive simplified model of bolt shank (steel bar) [6] considered directly in this study. Also, the characteristics of bolt shank ribs that have direct effect on bond shear strength are not considered directly in this study. These phenomena are taken into account indirectly by evaluating peak and residual shear strength of contact and their distribution along the bolt. It is also assumed that the medium is stress free (the only stress in medium is due to pullout tests).

\section{Rock bolt head Load-displacement relationships in complete bonding}

At low stress (load), the interfaces and the bolt bar remain elastic and the displacements are compatible. Unlike Aydan [3], Farmer [4] considered the surrounding rock as a deformable media. The free force diagram for the boltgrout-rock system as an idealized stress and deformation state is shown in Fig. $4[3,4]$. Note that the grouted bolt length in the bonded section $(L b)$ is relatively large and simply shown by $L$.

The definitions of the parameters in Fig. 4 are as follows: $r_{b}$ is the bolt radius, $r_{h}$ is the hole radius, $r_{o}$ is the radius of a circle in the rock outside which the influence of the bolt disappears, $\sigma_{0}$ is the axial stress on the bolt at the bolt head, $d x$ is an infinitesimal element length, $\sigma_{b x}$ is the stress in the bolt at distance $x$ from the bolt head, $d \sigma_{b x}$ is the variation of the bolt stress within the length $d x, u_{0}$ is the displacement or total elongation at the bolt head, $u_{b x}$ is the bolt displacement at distance $x, d u_{b x}$ is the amount of displacement within $d x, \tau_{r b, x}$ is the shear stress at the boltgrout interface (in radius $r_{b}$ ) at distance $x$ from the bolt head, $\tau_{r h, x}$ is the shear stress at the grout-rock interface (in radius $r_{h}$ ) at distance $x$ from the bolt head.

Considering force equilibrium in axial direction on a small section of the bolt, following expression is derived [4]:

$$
\frac{d \sigma_{b x}}{d x}=-\frac{2}{r_{b}} \tau_{r b, x}
$$

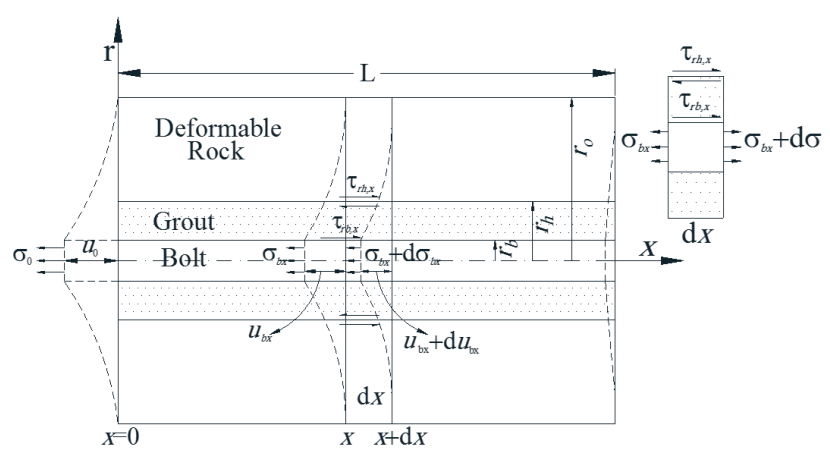

Fig. 4 Idealized stress and deformation field along the bolt in complete bonding and elastic condition (no de-bonding) [3] 
To solve Eq. (1), all parameters should be provided based on a single variable. Considering stress-strain as well as strain-displacement relationships of an elastic bar, Eq. (1) can be written based on displacement as:

$$
\frac{d^{2} u_{b x}}{d x^{2}}=\frac{2}{r_{b} E_{b}} \tau_{r b, x}
$$

Considering a linear relationship between the shear stress at the grout-bolt interface and the shear stress at a point perpendicular to the bolt axis $\left(\tau_{r, x}=\left(r_{b} / r\right) \tau_{r b, x}\right)$, the shear strength, $\tau_{r b, x}$, can be as a function of the bolt displacement. Thus, a homogeneous linear differential equation is derived as follows $[3,4,13]$ :

$$
\frac{d^{2} u_{b x}}{d x^{2}}-\alpha^{\prime 2} u_{b x}=0
$$

where $\alpha^{\prime 2}$ is defined based on different conditions as:

$$
\left\{\begin{array}{l}
\alpha^{\prime 2}=\frac{2 G_{g}}{E_{b} r_{b}\left(r_{h}-r_{b}\right)} \\
\alpha^{\prime 2}=\frac{2 G_{g}}{E_{b} r_{b}^{2}} \ln \frac{r_{h}}{r_{b}} \\
\alpha^{\prime 2}=\frac{2 G_{R} G_{g}}{E_{b} r_{b}^{2}\left[G_{R} \ln \left(\frac{r_{h}}{r_{b}}\right)+G_{g} \ln \left(\frac{r_{0}}{r_{h}}\right)\right]}
\end{array} .\right.
$$

The first relation of Eq. (4) is for a rigid rock mass with a thin grout annulus, the second one is related to a rigid rock mass with a thick grout annulus, and the third one is for a deformable rock mass with a thick grout annulus $[3,4]$. The general solution of Eq. (3) is:

$u_{b x}=c_{1} e^{\alpha^{\prime} x}+c_{2} e^{-\alpha^{\prime} x}$.

Where $c_{1}$ and $c_{2}$ are constants that are defined based on boundary condition $\left(\sigma_{b x}=\sigma_{0}\right.$ at $x=0 \& \sigma_{b x}=0$ at $\left.x=L\right)$. Considering that in most long rock bolts $L$ is significantly larger than $\frac{1}{\alpha^{\prime}}$, the distribution of displacement and stress along a rock bolt and shear stress on the bolt-grout interface for a general case (deformable rock and thick annulus) are [4]:

$$
u_{b x}=\frac{\sigma_{0}}{E_{b} \alpha^{\prime}} e^{-\alpha^{\prime} x}, \sigma_{b x}=\sigma_{0} e^{-\alpha^{\prime} x}, \tau_{r b, x}=\frac{r_{b} \alpha^{\prime} \sigma_{0}}{2} e^{-\alpha^{\prime} x} .
$$

Assuming $\alpha^{2}=\alpha^{\prime 2} r_{b}^{2}$, Eq. (6) is given as:

$$
u_{b x}=\frac{d_{b} \sigma_{0}}{2 E_{b} \alpha} e^{\frac{-2 \alpha}{d_{b}} x}, \sigma_{b x}=\sigma_{0} e^{\frac{-2 \alpha}{d_{b}} x}, \tau_{r b, x}=\frac{\alpha \sigma_{0}}{2} e^{\frac{-2 \alpha}{d_{b}} x} \text {. }
$$

Where $\alpha^{2}$ (for deformable rock and thick annulus) is given as:

$$
\alpha^{2}=\frac{2 G_{R} G_{g}}{E_{b}\left[G_{R} \ln \left(\frac{d_{h}}{d_{b}}\right)+G_{g} \ln \left(\frac{d_{o}}{d_{h}}\right)\right]} .
$$

In which $d_{b}=2 r_{b}, d_{h}=2 r_{h}, d_{o}=2 r_{o}$, and $G_{R}$ is the shear modulus of the rock, and $G_{g}$ is the shear modulus of the grout. Other parameters remain as defined previously.

It is important to note that the relations presented in Eq. (7) are independent of the bolt length. The displacement at the bolt head $(x=0)$ is given as $u_{b 0}=\frac{d_{b} \sigma_{0}}{2 E_{b} \alpha}$, which is not related to the bolt length. Generally, to determine the bolt head displacement, an integration should be taken along the bolt length to get the total elongation of the bolt, as follows:

$$
\left\{\begin{array}{l}
\delta=\int_{0}^{L} \varepsilon d x=\frac{1}{E_{b}} \int_{0}^{L} \sigma_{b x} d x=\frac{1}{E_{b}} \int_{0}^{L} \sigma_{0} e^{-\frac{2 \alpha}{d_{b}} x} d x \Rightarrow \\
\Rightarrow=\frac{\sigma_{0}}{E_{b}} \frac{d_{b}}{2 \alpha}\left[e^{-\frac{2 \alpha}{d_{b}} L}-1\right]
\end{array} .\right.
$$

Considering the fact that $L$ is significantly larger than $d_{b}$, the total elongation can be written as:

$\delta=\frac{d_{b} \sigma_{0}}{2 E_{b} \alpha}=\frac{d_{b} P_{0}}{2 A_{b} E_{b} \alpha} \Rightarrow P_{0}=\frac{2 A_{b} E_{b} \alpha}{d_{b}} \delta$.

$P_{0}$ is the applied load on the bolt head and $A_{b}$ is the bolt (bar) cross section area.

Equation (10) gives the load-displacement relation (a linear relationship) for the bolt head under elastic condition without de-bonding.

\section{Load-displacement curve of bolt head considering de-bonding and bolt failure}

Based on the presented model for assessing the interface shear stress distribution and the constitutive model of the bolt presented in Fig. (2) and Fig. (3) respectively, the evolution of the de-bonding process (moving decoupling front) and the bolt failure with increasing load on bolt head is classified in 4 different stages which are illustrated in Fig. (5) $[5,6]$.

It should be noted that $\mathrm{He}$ et al. [6] developed $\mathrm{Li}$ and Stillborg [5] proposed model by considering the bolt shank failure. They determined axial stress distribution along the short and long bolt. However, they did not present load-displacement curve of bolt head in pullout test. In this paper the bolt axial stresses are presented in a convenient way based on the assumed shear stress distribution 


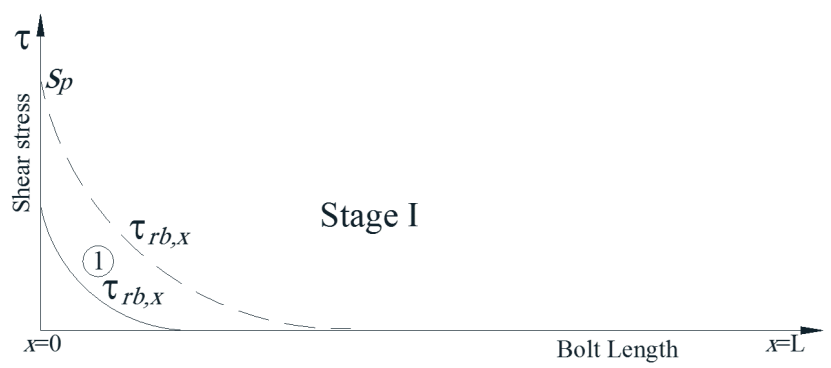

(a)

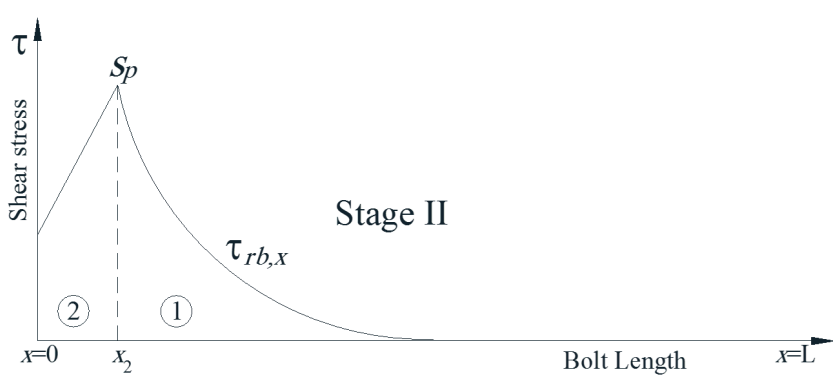

(b)

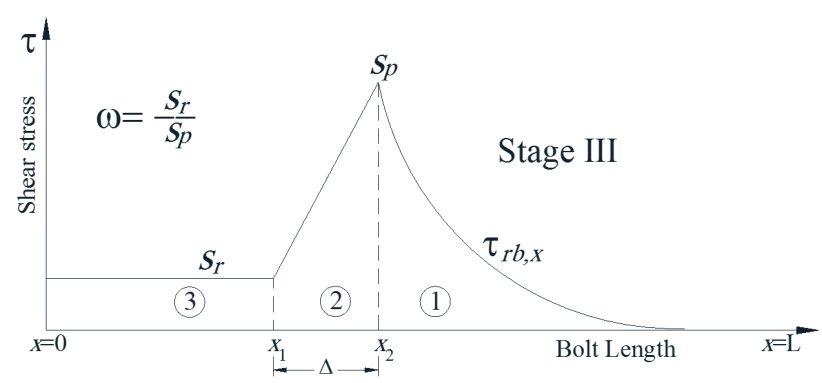

(c)

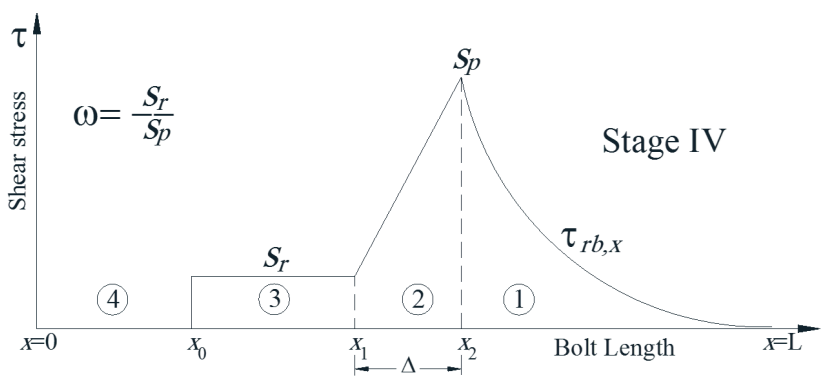

(d)

Fig. 5 Considered stages for distribution of shear stresses along the bolt, a) Stage I: elastic bar and complete bonding, b) Stage II: elastic bar and partial de-bonding, c) Stage III: elastic bar and de-bonding with residual shear strength, d) Stage IV: elasto-plastic bar with complete de-bonding $[5,6]$

in each stage of de-bonding. Then the equations are developed for determining the elongation of bolt head in each stage of de-bonding based on the applied load using a different integration method over the bolt length.

\section{Stage I: $P_{0} \leq P_{c r}^{I}$}

When the applied load on the bolt head $\left(P_{0}\right)$ is small, complete bonding and compatible deformation condition exist in the bonded section of the rock bolt (Fig. 5.a). This state was explained in the previous section. The shear stress at the interface $\left(\tau_{r b, x}^{I}\right)$, the bolt axial stress $\left(\sigma_{b x}^{I}\right)$, and the displacement (elongation) at the bolt head $\left(\delta^{I}\right)$ can be calculated using Eqs. (7)-(10). Note that superscript I refers to Stage I.

The applied load becomes maximal when the shear stress at the beginning of the grouted rock bolt (bolt head) reaches to the maximum shear strength $\left(\tau_{r b, 0}^{I}=S_{P}\right)$. In this situation, the critical (maximum allowed) pullout load for Stage $\mathrm{I}\left(P_{c r}^{I}\right)$ is:

$\sigma_{0}=\frac{2 S_{P}}{\alpha} \Rightarrow P_{c r}^{I}=\frac{2 S_{P}}{\alpha} A_{b}$.

When the applied load reaches its critical value, the maximum elongation at the bolt head is:

$\delta_{c r}^{I}=\delta_{M a x}^{I}=\frac{d_{b} P_{c r}^{I}}{2 A_{b} \mathrm{E}_{b} \alpha}=\frac{S_{P} d_{b}}{\alpha^{2} \mathrm{E}_{b}}$.

Theoretically, by defining the maximum displacement in the linear part of the load-displacement curve based on pullout test result, the can be determined using Eq. (12). But, practically, defining the from pullout test is not easy since the displacement is usually very small.

Stage II: $P_{c r}^{I}<P_{0} \leq P_{c r}^{I I}$

When the applied load exceeds $P_{c r}^{I}$, partial decoupling initiates from the loading point and propagates towards the far end of the bolt by increasing the load (Fig. 5.b). In this case, shear stress distribution is divided into two sections along the bolt. In Section 1 ( $x \in\left[x_{2}, L\right]$ ), deformations are compatible under full bonding conditions; and, as explained previously, the shear stress at the bolt-grout interface $\left(\tau_{r b, x}^{I I, 1}\right)$ decreases exponentially. In Section $2\left(x \in\left[0, x_{2}\right]\right)$, the shear stress at the interface $\left(\tau_{r b, x}^{I I, 2}\right)$ decreases linearly with the rate of $\frac{S_{P}-S_{r}}{\Delta}$. Note that superscript II, 1 and II,2 refers to sections 1 and 2 of Stage II. Thus, shear and axial stresses are derived as:

$\left\{\begin{array}{ll}\tau_{r b, x}^{I I, 1}=S_{P} e^{\frac{-2 \alpha}{d_{b}}\left(x-x_{2}\right)}, & x \in\left[x_{2}, L\right] \\ \tau_{r b, x}^{I I, 2}=S_{P}-\frac{x_{2}-x}{\Delta}(1-\omega) S_{P}, & x \in\left[0, x_{2}\right]\end{array}\right.$,

$\left\{\begin{array}{ll}\sigma_{b x}^{I I, 1}=\frac{2 S_{P}}{\alpha} e^{\frac{-2 \alpha}{d_{b}}\left(x-x_{2}\right)}, & x \in\left[x_{2}, L\right] \\ \sigma_{b x}^{I I, 2}=\frac{4 P_{0}}{\pi d_{b}^{2}}-\frac{4}{d_{b}}\left(1-\frac{2 x_{2}-x}{2 n}(1-\omega)\right) x S_{P}, & x \in\left[0, x_{2}\right]\end{array}\right.$. 
Where $d_{b}$ is the diameter of bolt, $\omega$ is the ratio of $S_{r}$ to $S_{p}$, and $\Delta$ is the distance in which $S_{p}$ decreases to $S_{r}$. Other parameters are the same as defined above.

The applied load reach its maximum - the critical pullout load for Stage II $\left(P_{c r}^{I I}\right)$ - when $x_{2}$ in Stage II $\left(x_{2}^{I I}\right)$ becomes equal to $\Delta$. As a result, the critical load is:

$$
P_{c r}^{I I}=\left(\frac{2}{\alpha}+\frac{2 \Delta}{d_{b}}(1+\omega)\right) S_{P} A_{b} .
$$

To define the location of $x_{2}^{I I}$ before reaching to $\Delta$, in Eq. (14) the condition $\sigma_{b x_{2}}^{I I, 1}=\sigma_{b x_{2}}^{I I, 2}$ should be satisfied when $x=x_{2}$. Thus, location of $x_{2}^{I I}$ can be defined by solving the derived quadratic equation as follows:

$$
\left\{\begin{array}{l}
x_{2}^{I I}=\frac{-b-\sqrt{b^{2}-4 a c}}{2 a} \\
a=\frac{2(1-\omega)}{\Delta d_{b}} S_{P}, b=-\frac{4 S_{P}}{d_{b}}, c=\frac{4 P_{0}}{\pi d_{b}^{2}}-\frac{2 S_{P}}{\alpha}
\end{array} .\right.
$$

To determine the elongation of the grouted bolt head the relation $\delta=\frac{1}{E_{b}} \int_{0}^{L} \sigma_{b x} d x$ with Eq. (14) is used. The total elongation of the bolt head in Stage II is the sum of the elongations in Sections 1 and $2\left(\delta^{I I}=\delta^{I, 1}+\delta^{I, 2}\right)$. The maximum elongation of Section 1 in Stage II equals to $\delta_{c r}^{I}\left(\delta^{I I, 1}=\delta_{c r}^{I}\right)$. Thus, total elongation $\left(\delta^{I I}=\frac{1}{E_{b}} \int_{0}^{x_{2}} \sigma_{b x}^{I, 2} d x+\delta_{c r}^{I}\right)$ is derived as:

$\delta^{I I}=\frac{1}{E_{b}}\left[\frac{4 P_{0}}{\pi d_{b}^{2}} x_{2}^{I I}-\frac{2 S_{P}\left(x_{2}^{I I}\right)^{2}}{3 d_{b}}\left(3-\frac{2(1-\omega)}{\Delta} x_{2}^{I I}\right)\right]+\frac{S_{P} d_{b}}{\alpha^{2} E_{b}}$.

The elongation (Eq. 17) reaches its maximum when $P_{0}=P_{c r}^{I I}$ and $x_{2}^{I I}=\Delta$ so:

$\delta_{c r}^{I I}=\delta_{\text {Max }}^{I I}=\frac{1}{E_{b}}\left[\frac{4 P_{c r}^{I I}}{\pi d_{b}^{2}} n-\frac{2 S_{P} n^{2}}{3 d_{b}}(1+2 \omega)\right]+\frac{S_{P} d_{b}}{\alpha^{2} E_{b}}$.

Stage III: $P_{c r}^{I I}<P_{0} \leq P_{c r}^{I I I}$

Once the applied load exceeds $P_{c r}^{I I}$, Stage III begins and the shear stress distribution along the bolt is divided into 3 sections (Fig. 5.c). Section $1\left(x \in\left[x_{2}, L\right]\right)$ is related to the full bonding condition. Partial de-bonding occurs in Section $2\left(x \in\left[x_{1}, x_{2}\right]\right)$ and shear stress $\left(\tau_{r b, x}^{I I I, 2}\right)$ decreases linearly from $S_{p}$ to $S_{r}$ within distance $\Delta$. In Section 3 $\left(x \in\left[0, x_{1}\right]\right)$, de-bonding appears with residual shear strength. The shear and axial stresses along the bolt in Stage III are defined as:

$$
\begin{aligned}
& \left\{\begin{array}{lrl}
\tau_{r b, x}^{I I I, 1}=S_{P} e^{\frac{-2 \alpha}{d_{b}}\left(x-x_{2}\right)}, & x \in\left[x_{2}, L\right] \\
\tau_{r b, x}^{I I I, 2}=\omega S_{P}+\frac{x-x_{1}}{\Delta}(1-\omega) S_{P}, & x \in\left[x_{1}, x_{2}\right], \\
\tau_{r b, x}^{I I I, 3}=S_{r}, & x \in\left[0, x_{1}\right]
\end{array}\right. \\
& \begin{cases}\sigma_{b x}^{I I I, 1}=\frac{2 S_{p}}{\alpha} e^{\frac{-2 \alpha}{d_{b}}\left(x-x_{2}\right)}, & x \in\left[x_{2}, L\right] \\
\sigma_{b x}^{I I I, 2}=\frac{4 P_{0}}{\pi d_{b}^{2}}-\frac{2 S_{p}}{d_{b}}\left(2 \omega x+\frac{(1-\omega)}{\Delta}\left(x-x_{1}\right)^{2}\right), & x \in\left[x_{1}, x_{2}\right] \\
\sigma_{b x}^{I I I, 3}=\frac{4 P_{0}}{\pi d_{b}^{2}}-\frac{2 S_{r}}{d_{b}} x, & x \in\left[0, x_{1}\right]\end{cases}
\end{aligned}
$$

Axial stresses are equal $\left(\sigma_{b x_{2}}^{I I I, 1}=\sigma_{b x_{2}}^{I I I, 2}\right)$ at $x_{2}$ (intersection of zone 1 and 2); so, the position of $x_{2}$ in Stage III ( $\left.x_{2}^{I I I}\right)$ is:

$x_{2}=x_{2}^{I I I}=\frac{1}{2 \omega}\left[\frac{2 P_{0}}{\pi d_{b} S_{P}}-\frac{d_{b}}{\alpha}-(1-\omega) \Delta\right]$.

To determine the displacement (elongation) of the bolt head as a result of the applied load in Stage III, integration $\delta=\frac{1}{E_{b}} \int_{0}^{L} \sigma_{b x} d x$ should be taken along the sections 1,2 , and 3. The total displacement of the bolt head is the sum of the elongation in each section $\left(\delta^{I I}=\delta^{I I I, 1}+\delta^{I I, 2}\right)$ :

$\delta^{I I I}=\frac{1}{E_{b}}\left[\frac{4 P_{0}}{\pi d_{b}^{2}} 2_{2}^{I I I}-\frac{2 \omega S_{P}}{d_{b}}\left(x_{2}^{I I I}-\Delta\right)^{2}-\frac{2 S_{P} \Delta}{3 d_{b}}\left[\Delta(1-4 \omega)+6 \omega x_{2}^{I I I}\right]\right]$ $+\frac{S_{P} d_{b}}{\alpha^{2} E_{b}}$

The total displacement of the Stage III can also be defined using equation $\delta^{I I}=\frac{1}{E_{b}} \int_{0}^{x_{1}} \sigma_{b x}^{I I, 3} d x+\delta_{c r}^{I I}$ as:

$\delta^{I I I}=\frac{1}{E_{b}}\left[\frac{4 P_{0}}{\pi d_{b}^{2}} x_{1}-\frac{2 \omega S_{P}}{d_{b}}\left(x_{1}\right)^{2}\right]+\delta_{c r}^{I I}$.

Note that results of Eqs. (22) and (23) are the same. Increasing the pull load results in two possible cases:

Case 1: By increasing the load to a maximum, the rock bolt is pulled out completely without bar failure. This occurs usually, in relatively short bolts or in low $S_{p}$. Equilibrium condition between the applied load and the interface shear force $\left(P_{0}=\pi d_{b} \int_{0}^{L} \tau_{r b, x} d x\right)$ gives:

$P_{0}^{I I I}=\pi d_{b}\left[S_{r} x_{1}+\frac{1}{2} S_{P} \Delta(1+\omega)+\frac{d_{b}}{2 \alpha} S_{P}\left(1-e^{-\frac{2 \alpha}{d_{b}}\left(\mathrm{~L}-x_{2}\right)}\right)\right]$. 
Derivation of Eq. (24) relative to $x_{2}$ solves the equation $x_{2}=L+\frac{d_{b}}{2 \alpha} \ln \left(\frac{1+\omega}{2}\right)$. Thus, the maximum applied load in Stage III for complete pull out of rock bolt without bolt shank failure is as follows:

$P_{0 M a x}^{I I I}=\pi d_{b} S_{P}\left[\omega\left(L+\frac{d_{b}}{2 \alpha} \ln \left(\frac{1+\omega}{2}\right)-\Delta\right)+\frac{1}{2} \Delta(1+\omega)+\frac{d_{b}}{2 \alpha}\left(\frac{1-\omega}{2}\right)\right]$.

Li and Stillborg [5] measured $P_{0 \mathrm{Max}}^{I I I}$ in a pull out test. Then, they determined $S_{p}$ by knowing or assuming all other parameters. It should be noted that they used an equation which differs from Eq. (25) due to a minor calculation error. This item is explained in detail in the appendix A.

Li and Stillborg [5] used only the maximum load needed for complete pullout (without bolt shank failure) for determining the bond shear strength. Other parameters are either known or should be assumed. The method is developed in this paper in which the bolt head load-displacement is used for determining bond shear strength.

Case 2: If the bolt length is large (long rock bolt) or $S_{p}$ is high, the rock bolt cannot be pulled out. The bolt shank will touch yield limit and Stage IV initiates. In this case Eq. (25) cannot be used to determine $S_{p}$.

Therefore, as long as the applied load is lower than the yield load of the bar, Stage III is applicable, which means that the critical load $\left(P_{c r}^{I I I}\right)$ is equal to bar yield load $\left(P_{y}=A_{b} \sigma_{y}\right)$.

$P_{c r}^{I I I}=P_{\mathrm{y}}$

\section{Stage IV: $P_{\mathrm{y}} \leq P_{0}$}

As soon as the applied pull load exceeds the steel yield load, Stage IV begins. Within some distance from the bolt head $\left(x_{0}\right)$ the bolt shank yields and obeys the elasto-plastic constitutive model of steel material as shown in Fig (3). Moreover, the shear strength at the interface becomes zero.

In Stage IV, the shear stress distribution along the bolt is divided into 4 sections (Fig. 5(d)). Section $1\left(x \in\left[x_{2}, L\right]\right)$ is related to the full bonding condition, Section $2\left(x \in\left[x_{2}, x_{1}\right]\right)$ is assigned to partial de-bonding, in Section $3\left(x \in\left[x_{0}, x_{1}\right]\right)$ de-bonding happens with residual shear strength, and in Section $4\left(x \in\left[0, x_{0}\right]\right)$ the steel bar yields and the shear strength is zero. The shear and axial stresses along the bolt in Stage IV are given as:

$$
\begin{cases}\tau_{r b, x}^{I V, 1}=S_{P} e^{\frac{-2 \alpha}{d_{b}}\left(x-x_{2}\right)}, & x \in\left[x_{2}, L\right] \\ \tau_{r b, x}^{I V, 2}=\omega S_{P}+\frac{x-x_{1}}{n}(1-\omega) S_{P}, & x \in\left[x_{1}, x_{2}\right], \\ \tau_{r b, x}^{I V, 3}=S_{r}, & x \in\left[x_{0}, x_{1}\right] \\ \tau_{r b, x}^{I V, 4}=0, & x \in\left[0, x_{0}\right]\end{cases}
$$

$$
\left\{\begin{array}{rlrl}
\sigma_{b x}^{I V, 1}= & \frac{2 S_{P}}{\alpha} e^{\frac{-2 \alpha}{d_{b}}\left(x-x_{2}\right)}, & x \in\left[x_{2}, L\right] \\
\sigma_{b x}^{I V, 2}=\frac{4 P_{0}}{\pi d_{b}^{2}}-\frac{2 S_{P}}{d_{b}}\left(2 \omega\left(x-x_{0}\right)+\frac{(1-\omega)}{\Delta}\left(x-x_{1}\right)^{2}\right), & x \in\left[x_{1}, x_{2}\right] \\
\sigma_{b x}^{I V, 3}=\frac{4 P_{0}}{\pi d_{b}^{2}}-\frac{4 S_{r}}{d_{b}}\left(x-x_{0}\right), & x \in\left[x_{0}, x_{1}\right] . \\
\sigma_{b x}^{I V, 4}=\frac{4 P_{0}}{\pi d_{b}^{2}} \rightarrow \sigma_{b x}^{I V, 4}=\sigma_{y}, \text { or } \sigma_{b x}^{I V, 4}=E_{t} \varepsilon_{x}, & \\
& \text { or } \sigma_{b x}^{I V, 4}=\sigma_{u}, \quad x \in\left[0, x_{0}\right] &
\end{array}\right.
$$

To define the total displacement (elongation) of the bolt head in Stage IV, the displacement of Section $4\left(\delta_{b, y}^{I V, 4}\right)$, in which the bolt shank is yielded or passed the yield limit should be added to the elongation of the Sections 1 to 3 $\left(\delta^{I V, 1,2,3}=\delta^{I V, 1}+\delta^{I V, 2}+\delta^{I V, 3}\right)$. It is important to note that the location of is considered to be constant.

Depending on the amount of the applied load in Stage IV which may be $P_{0}=P_{y}=A_{b} \sigma_{y}, P_{y}<P_{0}<P_{u}$ or $P_{0}=P_{u}=A_{b} \sigma_{u}$ the strain of the bolt shank is defined from Fig. (3). Then, the displacement of Section 4 is determined as follows:

$\delta^{I V, 4}=\varepsilon x_{0} \rightarrow \delta^{I V, 4}=\left(\varepsilon_{h 1}-\varepsilon_{y}\right) x_{0}$, or
$\delta^{I V, 4}=\left(\varepsilon_{h 2}-\varepsilon_{y}\right) x_{0}$, or $\delta^{I V, 4}=\left(\varepsilon_{u}-\varepsilon_{y}\right) x_{0}$.

To determine the elongation of Sections 1 to 3, all relations presented in Stage III are applicable with a new position of $x_{2}$ and $x_{1}$, which are as follows:

$$
\left\{\begin{array}{l}
x_{2}=x_{2}^{I V}=\frac{1}{2 \omega}\left[\frac{2 P_{0}}{\pi d_{b} S_{P}}-\frac{d_{b}}{\alpha}-(1-\omega) \Delta\right]+x_{0} \\
x_{1}=x_{1}^{I V}=x_{2}^{I V}-\Delta
\end{array} .\right.
$$

The displacements (elongations) of the Sections 1 to 3 are given as:

$$
\begin{cases}\delta^{T, 1}=\frac{S_{P} d_{b}}{E_{b} \alpha^{2},} & x \in\left[x_{2}, L\right] \\ \delta^{I, 2}=\frac{1}{E_{b}}\left[\frac{4 P_{0}}{\pi d_{b}^{2}} \Delta-\frac{2 S_{P} \Delta}{3 d_{b}}\left[\Delta(1-4 \omega)+6 \omega\left(x_{2}-x_{0}\right)\right]\right], & x \in\left[x_{1}, x_{2}\right] . \\ \delta^{I, 3}=\frac{1}{E_{b}}\left[\frac{4 P_{0}}{\pi d_{b}^{2}}\left(x_{1}-x_{0}\right)-\frac{2 S_{r}}{d_{b}}\left(x_{1}^{2}-x_{0}^{2}\right)+\frac{4 S_{r}}{d_{b}} x_{0}\left(x_{1}-x_{0}\right)\right], & x \in\left[x_{0}, x_{1}\right]\end{cases}
$$


Thus the total displacement of the bolt head is the sum of the elongations $\left(\delta^{I V}=\delta^{I V, 1}+\delta^{I V, 2}+\delta^{I V, 3}+\delta^{I V, 4}\right)$.

In the Sections 1 to 3 of the Stage IV, equilibrium conditions between the applied load on the bolt head and the interface shear force $\left(P_{0}=\pi d_{b} \int_{0}^{L} \tau_{r b, x} d x\right)$ changes Eq. (24) to: $P_{0}^{I V}=\pi d_{b}\left[S_{r}\left(x_{1}-x_{0}\right)+\frac{1}{2} S_{P} \Delta(1+\omega)+\frac{d_{b}}{2 \alpha} S_{P}\left(1-e^{-\frac{2 \alpha}{d_{b}}\left(L-x_{2}\right)}\right)\right]$.

The derivation of Eq. (32) relative to $x_{2}$ gives the maximum load needed for the complete pull out of the bolt in Stage IV by considering bolt shank failure as follows: (33)

$P_{0 M a x}^{I V}=\pi d_{b} S_{P}\left[\omega\left(L+\frac{d_{b}}{2 \alpha} \ln \left(\frac{1+\omega}{2}\right)-\Delta-x_{0}\right)+\frac{1}{2} \Delta(1+\omega)+\frac{d_{b}}{2 \alpha}\left(\frac{1-\omega}{2}\right)\right]$.

Depending on the conditions, either the bolt shank failure occurs or bolt pull out happens. As mentioned before, Eq. (33) differs from the equation that Li and Stillborg [5] presented in their paper (due to a minor error, as explained in appendix A).

\section{Determining bond shear strength}

The presented analytical solution can be used to determine load-displacement curve of the grouted rock bolt head. Some input parameters such as rock bolt specification, hole diameter, grout, and rock mass parameters are known. On the contrary, the bond shear strength parameters such as $S_{p}, \omega, \Delta, x_{0}$ are undetermined. To define these parameters based on load-displacement curve of the bolt head obtained in pull tests, a trial and error method is used. By assuming initial parameters (based on previous experiences) for bond shear strength, a load-displacement curve is derived using the presented analytical method. Comparing the obtained curve with the recorded one in pullout test reveals that how much the assumed parameters are close to the realty. A flowchart for implementation of this method is given in appendix B, which is programmed in Matlab. This method is used in obtaining the shear strength parameters of two experimental pullout tests.

\subsection{Rong et al.'s pullout test}

Rong et al. [14] performed a pullout test on a rock bolt with $32 \mathrm{~mm}$ diameter and $1 \mathrm{~m}$ bond length anchored in a concrete block with compressive strength of $30 \mathrm{MPa}$ [14]. The comparison of the analytically obtained load-displacement curve with the pullout test result is presented in Fig. 6. The two results are in good agreement. The Root Mean Square Error (RMSE) method is used to measure the amount of error between the predicted and the measured displacements

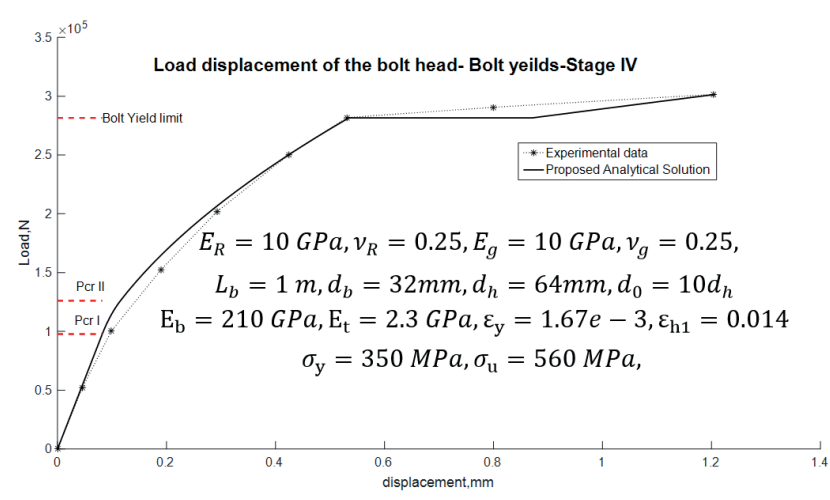

Fig. 6 Comparison of the bolt head load-displacement curve obtained analytically with the Rong's pullout test results

Table 1 Determined shear strength parameters for Rong's pullout test

\begin{tabular}{cccccc}
\hline$x_{0}(\mathrm{~mm})$ & $x_{1}(\mathrm{~mm})$ & $x_{2}(\mathrm{~mm})$ & $\Delta(\mathrm{mm})$ & $\omega$ & $S_{p}(\mathrm{MPa})$ \\
\hline 26 & 417.8 & 467.8 & 50 & 0.65 & 6.85 \\
\hline
\end{tabular}

under applied pull load. The RMSE value for this test is 0.013 for the loads lower than the bolt yield load. The input parameters of the pullout test, of which some are assumed, are also provided in Fig. 6 . The determined bolt-grout shear strength parameters are presented in Table 1.

Some researchers used Rong's pullout test for validation of their proposed methods $[8-11,15,16]$. Most of them used tri-linear shear bond-slip model proposed by Benmokarne [7] incorporating different peak shear strength for a single pullout test. Except Ma et al. [10], other authors did not consider yielding of the bolt shank. Instead, they modeled the bolt shank yielding with small residual shear strength at contact.

\subsection{Liu et al. pullout test}

Liu et al. [17] performed pullout tests on fully grouted rock bolts with a diameter of $42 \mathrm{~mm}$ and a length of $3 \mathrm{~m}$. These were embedded in a concrete block with an uniaxial compressive strength of $27 \mathrm{MPa}$ [17]. Fig. 7 shows the comparison between the obtained analytical load-displacement curve and the experimental results. The proposed analytical solution models the load transfer mechanism from bolt to rock and is able to predict the load-displacement curve of the bolt head, which agrees well with the experimental results under tensile loading. The RMSE value for this test is 0.008 for the loads lower than the bolt yield load.

Note that there are minor difference between analytical predictions and the test results after yielding of the bolt shank. This is mainly due to the considered simplification in the steel constitutive model. The evaluated boltgrout shear strength parameters for this pullout test are presented in Table 2. 


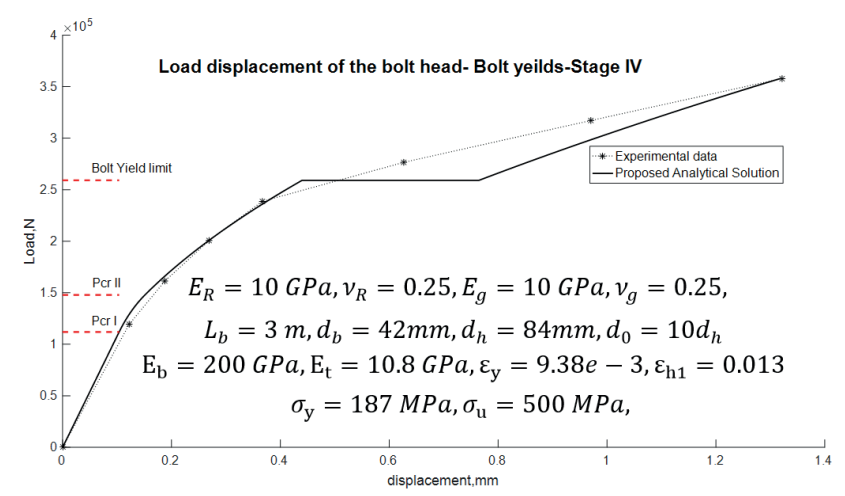

Fig. 7 Comparison of the rock bolt head load-displacement curve obtained analytically with the Liu's pullout test results

Table 2 Determined shear strength parameters for Liu's pullout test

\begin{tabular}{cccccc}
\hline$x_{0}(\mathrm{~mm})$ & $x_{1}(\mathrm{~mm})$ & $x_{2}(\mathrm{~mm})$ & $\Delta(\mathrm{mm})$ & $\omega$ & $S_{p}(\mathrm{MPa})$ \\
\hline 27 & 769.2 & 869.2 & 100 & 0.65 & 3.3 \\
\hline
\end{tabular}

It is interesting to note that the characteristics of the two bolts in the pullout tests are different from each other (such as bolt diameter, bolt length, bolt shank yield stress ...). The shape of the load-displacement obtained in tests are also different. So, the evaluated bond shear strength parameters are different accordingly (compare the parameters given in Table 1 with Table 2).

Numerical methods can also be used for determining the load-displacement curve of the bolt head. But for evaluating the bond shear strength parameters several modelling may be needed. The analytical method has the priority to evaluate a particular parameter effect in a more convenient way.

\section{Conclusions}

In this paper grouted bolt bond shear strength is determined using an analytical method. First, the load transfer mechanism from the bolt to the rock mass under a pull load is investigated comprehensively, by considering two possible cases including rock bolt complete pullout and bolt

\section{References}

[1] Lardner, W. E., Littlejohn, G. S. "Suggested method for rock anchorage testing", International Journal of Rock Mechanics and Mining Sciences \& Geomechanics Abstracts, 22(2), pp. 71-83, 1985.

https://doi.org/10.1016/0148-9062(85)92329-0

[2] ASTM "ASTM D4435, Standard Test Method for Rock Bolt Anchor Pull Test", ASTM International, West Conshohoken, PA, 2013.

https://doi.org/10.1520/D4435-13E01

[3] Aydan, Ö. "Rock Reinforcement and Rock Support", 1st ed., CRC Press, London, UK, 2018.

https://doi.org/10.1201/9781315104201 shank failure. Then, the load-displacement of the rock bolt at the head is determined. A flowchart is provided for determining the bond shear strength using trial and error method that is coded in Matlab. A verification of the proposed method is done using two pullout test results, which show good agreement between the analytical predictions and the experimental tests results.

Since the goal is to define the shear strength parameters $\left(S_{p}, \omega, \Delta, x_{0}\right)$ based on experimental results, following items should be considered:

1. The $S_{p}$ is the most important parameter both before and after the bolt yielding point. This item defines the critical locations, which should match the experimental output (for example, if either bolt pullout or failure occurs).

2. The $\Delta$ mainly defines the location of $P_{c r}^{I I}$ and the slope of the load-displacement curve after $P_{c r}^{I I}$. It has minor effect on the curve after bolt failure.

3 . The $\omega$ mainly determines the slope of the load-displacement curve after the location of $P_{c r}^{I I}$. It has little effect on the curve after bolt failure.

4. The $x_{0}$ (constant value) mainly determines the shape of the curve after bolt failure and has a considerable effect.

Due to simplification considered in steel constitutive model after failure, the predictions of the analytical model slightly differ from real pull out test results. This can be modified by introducing two or three linear behavior (between $\varepsilon_{h 1}$ and $\varepsilon_{h 2}$ ) for steel failure.

\section{Acknowledgement}

The authors would like to thank the reviewers for their valuable comments to improve this paper. We also would like to appreciate Dr. Philippe Nater for his comments to enhance the paper.

[4] Farmer, I. W. "Stress distribution along a resin grouted rock anchor", International Journal of Rock Mechanics and Mining Sciences \& Geomechanics Abstracts, 12(11), pp. 347-351, 1975. https://doi.org/10.1016/0148-9062(75)90168-0

[5] Li, C., Stillborg, B. "Analytical models for rock bolts", International Journal of Rock Mechanics and Mining Sciences, 36(8), pp. 10131029, 1999.

https://doi.org/10.1016/S1365-1609(99)00064-7

[6] He, L., An, X. M., Zhao, Z. Y. "Fully Grouted Rock Bolts: An Analytical Investigation", Rock Mechanics and Rock Engineering, 48(3), pp. 1181-1196, 2015.

https://doi.org/10.1007/s00603-014-0610-0 
[7] Benmokrane, B., Chennouf, A., Mitri, H. S. "Laboratory evaluation of cement-based grouts and grouted rock anchors", International Journal of Rock Mechanics and Mining Sciences \& Geomechanics Abstracts, 32(7), pp. 633-642, 1995.

https://doi.org/10.1016/0148-9062(95)00021-8

[8] Ren, F. F., Yang, Z. J., Chen, J. F., Chen, W. W. "An analytical analysis of the full-range behaviour of grouted rockbolts based on a tri-linear bond-slip model", Construction and Building Materials, 24(3), pp. 361-370, 2010.

https://doi.org/10.1016/j.conbuildmat.2009.08.021

[9] Blanco Martín, L., Tijani, M., Hadj-Hassen, F. "A new analytical solution to the mechanical behaviour of fully grouted rockbolts subjected to pull-out tests", Construction and Building Materials, 25(2), pp. 749-755, 2011.

https://doi.org/10.1016/j.conbuildmat.2010.07.011

[10] Ma, S., Nemcik, J., Aziz, N. "An analytical model of fully grouted rock bolts subjected to tensile load", Construction and Building Materials, 49, pp. 519-526, 2013.

https://doi.org/10.1016/j.conbuildmat.2013.08.084

[11] Ma, S., Zhao, Z., Nie, W., Zhu, X. "An Analytical Model for Fully Grouted Rockbolts with Consideration of the Pre- and Postyielding Behavior", Rock Mechanics and Rock Engineering, 50, pp. 3019-3028, 2017.

https://doi.org/10.1007/s00603-017-1272-5

[12] Windsor, C. R. "Rock reinforcement systems", International Journal of Rock Mechanics and Mining Sciences, 34(6), pp. 919951, 1997.

https://doi.org/10.1016/S1365-1609(97)80004-4

\section{Appendix A}

Li and Stillborg [5] proposed a back-calculation method to evaluate bolt-grout interface peak shear strength. In this method a bolt should be completely pulled out before bolt shank starts to yield. Only the maximum load should be recorded, and the rest of the parameters either are known (such as $d_{b}, E_{b} \ldots$ ) or assumed (such as $\omega, \Delta, \ldots$ ). Then, the unknown peak shear strength $\left(S_{p}\right)$ is determined using the equation as follows:

$$
P_{\text {omax }}=\pi d_{b} S_{P}\left[\omega\left(L+\frac{d_{b}}{2 \alpha} \ln \omega-\Delta-x_{0}\right)+\frac{1}{2} \Delta(1+\omega)+\frac{d_{b}}{2 \alpha}(1-\omega)\right] .
$$

[13] Hyett, A. J., Moosavi, M., Bawden, W. F. "Load distribution along fully grouted bolts, with emphasis on cable bolt reinforcement", International Journal for Numerical and Analytical Methods in Geomechanics, 20(7), pp. 517-544, 1996.

https://doi.org/10.1002/(SICI)1096-9853(199607)20:7<517::AIDNAG833>3.0.CO;2-L

[14] Rong, G., Zhu, H., Zhou, C. "Testing study on working mechanism of fully grouted bolts of thread steel and smooth steel", Chinese Journal of Rock Mechanics and Engineering, 23(3), pp. 469-475, 2004. (in Chinese)

[15] Nemcik, J., Ma, S., Aziz, N., Ren, T., Geng, X. "Numerical modelling of failure propagation in fully grouted rock bolts subjected to tensile load", International Journal of Rock Mechanics and Mining Sciences, 71, pp. 293-300, 2014. https://doi.org/10.1016/j.ijrmms.2014.07.007

[16] Ma, S., Zhao, Z., Nie, W., Gui, Y. "A numerical model of fully grouted bolts considering the tri-linear shear bond-slip model", Tunnelling and Underground Space Technology, 54, pp. 73-80, 2016.

https://doi.org/10.1016/j.tust.2016.01.033

[17] Liu, B., Li, D., Duan, Y., Jin, G., Tian, N. "Experimental study of bond-slip relationship between bolt and mortar and theoretical solution to failure process", Chinese Journal of Rock Mechanics and Engineering, 30(1), pp. 2790-2797, 2011. (in Chinese)

In which $P_{\text {omax }}$ is the maximum pullout load which is recorded in pullout test. Then, $S_{p}$ is calculated by knowing all other parameters. At first, the procedures for obtaining this equation is presented. Then, the mentioned minor error is explained in detail.

Considering the shear strength distribution model along the bolt (as shown in Fig. 2), the applied load on bolt head is in equilibrium state with the summation of shear force along the bolt. So we can write:

$P_{o}=\pi d_{b} \int_{0}^{L} \tau_{r b, x} d x=\pi d_{b}\left(\int_{x_{0}}^{x_{1}} \tau_{r b, x} d x+\int_{x_{1}}^{x_{2}} \tau_{r b, x} d x+\int_{x_{2}}^{L} \tau_{r b, x} d x\right)$

The distribution of $\tau_{r b, x}$ in each section is known based on the assumed model. The result of integration is:

$P_{o}=\pi d_{b} \int_{0}^{L} \tau_{r b, x} d x=\pi d_{b}\left[S_{r}\left(x_{1}-x_{0}\right)+S_{r}\left(x_{2}-x_{1}\right)+\frac{\left(x_{2}-x_{1}\right)\left(S_{P}-S_{r}\right)}{2}+\frac{d_{b}}{2 \alpha} S_{P}\left(1-e^{-\frac{2 \alpha}{d_{b}}\left(L-x_{2}\right)}\right)\right]$

Simplification results in the following equation:

$P_{o}=\pi d_{b}\left[S_{r}\left(x_{1}-x_{0}\right)+\frac{1}{2}(1+\omega) \Delta S_{r}+\frac{d_{b}}{2 \alpha} S_{P}\left(1-e^{-\frac{2 \alpha}{d_{b}}\left(L-x_{2}\right)}\right)\right]$
This equation is also given by Li and Stillborg [5]. To find the maximum applied load $\left(P_{\text {omax }}\right)$, the critical point of $x_{2}$ should be found by derivation of $P_{o}$ relative to $x_{2}$. This is the key point which results in two different equation for $P_{\text {omax }}$. $\mathrm{Li}$ and Stillborg took derivative as follows $\left(x_{1}=x_{2}-\Delta\right)$ : 


$$
\frac{\partial P_{o}}{\partial x_{2}}=\pi d_{b}\left[S_{r}+\frac{d_{b}}{2 \alpha} S_{P}\left(-\frac{2 \alpha}{d_{b}} e^{-\frac{2 \alpha}{d_{b}}\left(L-x_{2}\right)}\right)\right]=0 .
$$

Solving this equation gives $x_{2}=L+\frac{d_{b}}{2 \alpha} \ln \omega$. Then the Eq. (34) is obtained. It is important to note that the middle part is not considered in derivative.

On the contrary, the authors used Eq. (36) for derivation (derivation of all items relative to $\mathrm{x}_{-}$2). In this case the derivation will be as follows:

$$
\frac{\partial P_{o}}{\partial x_{2}}=\pi d_{b}\left[\frac{S_{P}(1+\omega)}{2}+\frac{d_{b}}{2 \alpha} S_{P}\left(-\frac{2 \alpha}{d_{b}} e^{-\frac{2 \alpha}{d_{b}}\left(L-x_{2}\right)}\right)\right]=0 .
$$

Solving this equation will give $x_{2}=L+\frac{d_{b}}{2 \alpha} \ln \left(\frac{1+\omega}{2}\right)$. By substituting the $x_{2}$ in Eq. (36) or Eq. (37) the following equation is derived:

$$
P_{\text {omax }}=\pi d_{b} S_{P}\left[\omega\left(L+\frac{d_{b}}{2 \alpha} \ln \left(\frac{1+\omega}{2}\right)-\Delta-x_{0}\right)+\frac{1}{2} \Delta(1+\omega)+\frac{d_{b}}{2 \alpha}\left(\frac{1-\omega}{2}\right)\right] .
$$

This is the same equation as Eq. (25). As it is shown in this appendix the is determined by two different equation due to two differentiation method.

\section{Appendix B}

A flowchart is given in Fig. 8 which presents the procedure for determining the bond shear strength parameters. A Matlab code is prepared based on this flowchart.

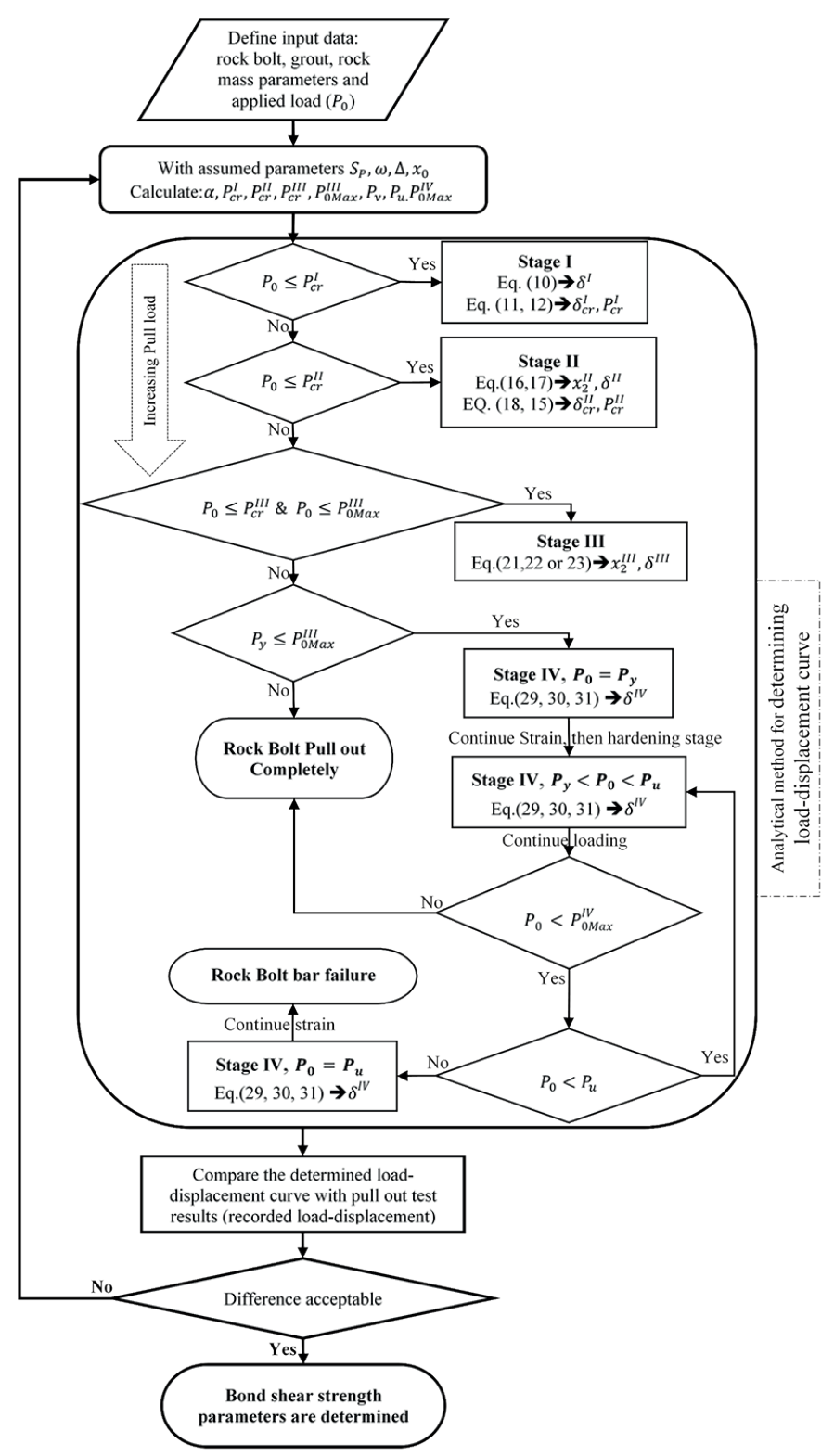

Fig. 8 Flowchart for determining the bolt bond shear strength parameters 